\title{
Pengaruh Pengembangan Karir, Motivasi Dan Kompetensi Terhadap Kinerja Pegawai Dinas Ketahanan Pangan Provinsi Kalimantan Tengah
}

\author{
Hendra Julianto $S^{1)}$ \\ Usup Riassy Christa ${ }^{2}$ ) \\ Deddy Rakhmad Hidayat ${ }^{3)}$ \\ Fakultas Ekonomi dan Bisnis \\ Universitas Palangka Raya, Indonesia \\ e-mail: hendrajulianto62@gmail.com
}

\begin{abstract}
Abstrak
Tujuan, - Tujuan dari penelitian ini adalah untuk mengetahui dan mendapatkan kajian tentang pengaruh pengembangan karir, motivasi dan kompetensi terhadap kineja pegawai Dinas Ketahanan Pangan Provinsi Kalimantan Tengah.

Desain/Methodologi/Pendekatan - Penelitian ini merupakan penelitian deskriptif kuantitatif dengan jumlah sebanyak 60 responden. Pengujian instrumen menggunakan uji validitas dan reliabilitas. Sedangkan metode analisis data menggunakan analisis regresi linear berganda dengan uji t, uji $\mathrm{F}$ dan $\mathrm{R}^{2}$,

Temuan penelitian - Hasil Penelitian menunjukan bahwa pengembangan karir berpengaruh positif signifikan terhadap kinerja pegawai, motivasi berpengaruh positif signifikan terhadap kinerja pegawai, kompetensi berpengaruh positif signifikan terhadap kinerja pegawai, pengembangan kari,motivasi dan kompetensi berpengaruh positif signifikan secara bersama-sama terhadap kinerja pegawai.
\end{abstract}

Kata kunci: Pengembangan Karir,Motivasi,Kompetensi,Kinerja pegawai

\section{The Effect Of Career Development, Motivation And Competence Of The Department Of Food Security Of Central Kalimantan Province}

\begin{abstract}
Purpose, - The purpose of this research is to find out and obtain a study of the influence of career development, motivation and competence on the performance of employees of the Department of Food Security of Central Kalimantan Province.

Design/methodology/approach - This research is a quantitative descriptive study with a total of 60 respondents. The instrument testing uses validity and reliability tests. While the data analysis method uses multiple linear regression analysis with $t$ test, $F$ test and $R^{2}$.

Findings - The results showed that career development had a significant positive effect on employee performance, motivation had a significant positive effect on employee performance, Competence has a significant positive effect on employee performance, self-development, motivation and competence has a significant positive effect together on employee performance.
\end{abstract}

Yeywords: Career Development, Motivation, Competence, Employee Performance

Jurnal Manajemen Sains dan Organisasi Vol 1, No 3, 2020 pp. $192-202$ FEB UPR Publishing $2685-4724$
Hendra Julianto S, Usup Riassy Christa, Deddy Rakhmad Hidayat. Published in the Jurnal Manajemen sains dan Organsasi. Published by FEB UPR Publishing Limited. This article is published under the Creative Commons Attribution (CC BY 4.0) licence. Anyone may reproduce, distribute, translate and create derivative works of this article (for both commercial and non-commercial purposes), subject to full attribution to the original publication and authors. 


\section{PENDAHULUAN}

Masalah kinerja pegawai yang sering kali terjadi di instansi pemerintah karena adanya perilaku yang berbeda-beda diantara individu.Pengembangan karir salah satu faktor yang mempengaruhi kinerja pegawai.Menurut Handoko (2014) Pengembangan karir adalah peningkatan pribadi yang dilakukan seseorang untuk mencapai tujuan suatu rencana karir dan peningkatan oleh departemen personalia untuk mencapai suatu rencana kerja sesuai dengan jalur atau jenjang organisasi. Dengan adanya pengembangan karir pegawai dapat meningkatkan kemampuan individu yang merencanakan karir dimasa sekarang dan masa yang akan datang. Pegawai juga membutuhkan motivasi untuk melakukan suatu pekerjaan agar timbul suatu semangat atau kegairahan dalam bekerja. menurut Wibowo (2011) motivasi adalah sesuatu yang menimbulkan dorongan atau semangat kerja atau pendorong semangat kerja. Pengembangan karir dan motivasi yang baik maka kompetensi yang baik akan tercipta, sehingga kinerja yang baik akan ikut baik juga. Menurut wibowo (2010) kompetensi adalah suatu kemampuan untuk melaksanakan atau melakukan suatu pekerjaaan yang di landasi atas keterampilan dan pengetahuan serta didukung oleh sikap kerja yang dituntut oleh pekerjaan tersebut. Kompetensi pegawai yang baik dan memadai berarti akan dapat menyelesaikan pekerjaannya dengan baik sesuai dengan waktu dan target yang telah di tetapkan dalam program kerja. Berikut adalah tabel absensi pegawai Dinas Ketahanan Pangan Provinsi Kalimantan Tengah selama bulan Januari-september 2018

Tabel 1 Data Absensi pegawai Dinas Ketahanan Pangan Provinsi Kalimantan Tengah, pada bulan Januari-september 2018.

\begin{tabular}{|c|c|c|c|c|c|c|c|c|}
\hline \multicolumn{9}{|c|}{ ABSENSI } \\
\hline Bulan & $\begin{array}{c}\text { Hari } \\
\text { Kerja }\end{array}$ & Sakit & Izin & $\begin{array}{c}\text { Tanpa } \\
\text { Keterangan }\end{array}$ & Cuti & $\begin{array}{l}\text { Dinas } \\
\text { Luar }\end{array}$ & $\begin{array}{l}\text { Dinas } \\
\text { Dalam }\end{array}$ & $\begin{array}{l}\text { Persentase } \\
\text { ketidakhadi } \\
\text { ran (tanpa } \\
\text { keterangan) } \\
\text { pegawai }(\%)\end{array}$ \\
\hline Januari & 22 & 7 & 1 & 68 & 7 & 61 & - & $5,15 \%$ \\
\hline Februari & 19 & - & 1 & 25 & 15 & 80 & 11 & $2,19 \%$ \\
\hline Maret & 21 & 17 & 8 & 28 & 7 & 140 & 4 & $2,22 \%$ \\
\hline April & 21 & - & 3 & 30 & 9 & 130 & 5 & $2,38 \%$ \\
\hline Mei & 20 & - & 2 & 33 & 18 & 126 & - & $2,75 \%$ \\
\hline Juni & 12 & - & - & 35 & - & 86 & - & $4,86 \%$ \\
\hline Juli & 22 & 2 & 6 & 28 & - & 148 & 19 & $2,12 \%$ \\
\hline Agustus & 21 & 4 & 5 & 30 & 26 & 96 & 4 & $2,38 \%$ \\
\hline September & 19 & - & 2 & 28 & 52 & 107 & 32 & $2,45 \%$ \\
\hline Rata-rata & 19,69 & 3,33 & 3,11 & 34,22 & 14,89 & 108,22 & 9,33 & 2,94 \\
\hline
\end{tabular}

Sumber: Dinas Ketahanan Pangan Provinsi Kalimantan Tengah (2019)

Berdasarkan Tabel 1 diatas dapat dilihat bahwa tingkat absensi terbesar terjadi pada bulan Januari,Mei,dan Juni,karena pada bulan tersebuat bertepatan dengan awal tahun dan hari besar keagamaan, sehingga banyak pegawai yang membolos satu sampai tiga hari dengan alasan berlibur di luar kota dan perjalanan pulangnya terlambat. Hal ini dapat berpengaruh secara negatif rendahnya kinerja pegawai. 


\section{TINJAUAN PUSTAKA}

Raymond .A Noe (2010), menyatakan bahwa Pengembangan karir di artikan sebagai perolehan pengetahuan, keterampilan, dan prilaku yang meningkatkan kemampuan karyawan untuk memenuhi perubahan persyaratan pekerjaan serta tuntutan klien dan pelanggan. Harlie (2012),dalam penelitiannya menyatakan bahwa pengambangan karir terdapat pengaruh yang signifikan terhadap kinerja pegawai.

H1: Pegembangan karir berpengaruh positif signifikan terhadap kinerja pegawai.

Suwanto dan Donni Juni Priansa (2011), menyatakan bahwa motivasi berasal dari kata latin (movere) yang berarti dorongan, daya pengerak atau kekuatan yang menyebabkan suatu tindakan atau perbuatan. Motivasi mempersoalkan cara mengarahkan daya dan potensi bawahan agar mau bekerja secara produktif dalam mencapai dan mewujudkan tujuan yang telah ditentukan. Manalu (2012). Dalam penelitiannya menyatakan bahwa motivasi terdapat pengaruh yang signifikan terhadap kinerja pegawai.

H2: Motivasi berpengaruh positif signifikan terhadap kinerja pegawai.

Spencer dalam Moeheriono (2012), menyatakan bahwa kompetensi adalah karakteristik yang mendasari seseorang berkaitan dengan efektivitas kinerja individu dalam pekerjaannya atau karakteristik individu yang memiliki hubungan kasual atau sebab-akibat dengan kriteria yang dijadikan acuan, efektif atau kinerja prima ditempat kerja pada situasi tertentu. Hendriani (2015), dalam penelitiannya menyatakan bahwa kompetensi terdapat pengaruh yang signifikan terhadap kinerja pegawai.

H3: Kompetensi berpengaruh positif signifikan terhadap kinerja pegawai.

Syamir Torang (2013), menyatakan bahwa kinerja (performance) adalah kuantitas atau kualitas hasil kinerja individu atau kelompok didalam organisasi dalam melaksanakan tugas pokok dan fungsi yang berpedoman pada performa, standar operasional prosedur, kriteria dan ukuran yang telah ditetapkan atau yang berlaku dalam organisasi. Afriska Tris (2017) dalam penelitinnya menyatakan bahwa pengembangan karir, motivasi dan kompetensi terdapat pengaruh yang signifikan terhadap kinerja pegawai.

H4: Pengembangan karir, Motivasi dan Kompetensi berpengaruh positif signifikan terhadap kinerja pegawai

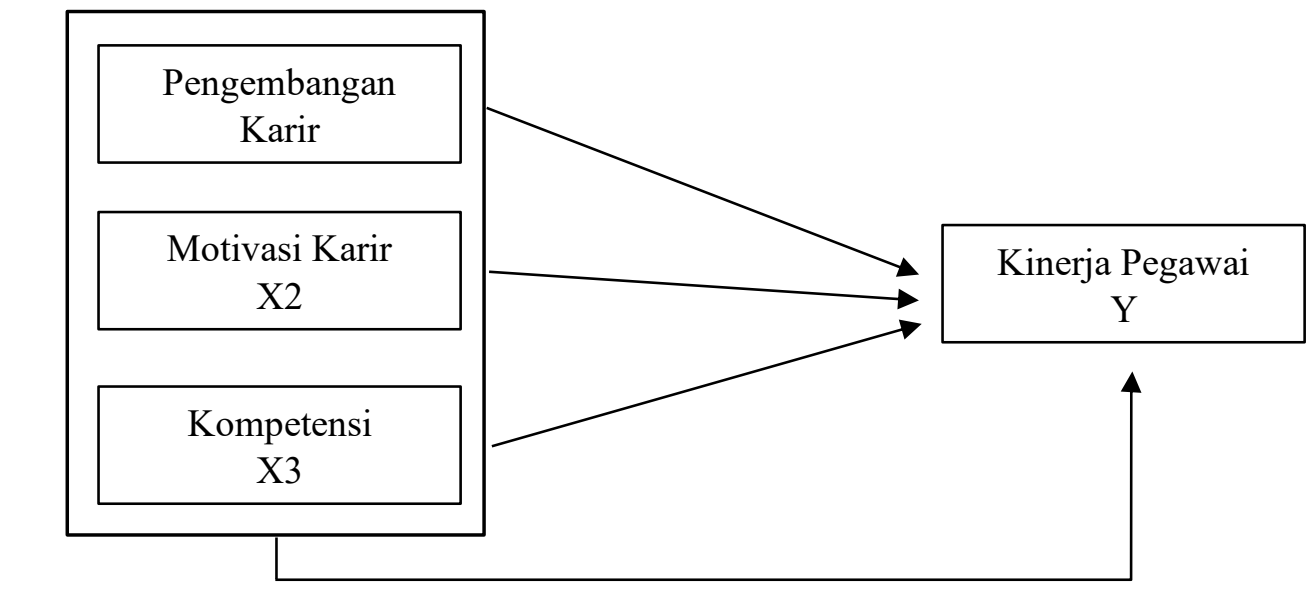

Sumber: Dikembangkan untuk penelitian ini( 2019)

Gambar 1. Kerangka Berpikir 


\section{METODE PENELITIAN}

Penelitian ini merupakan penelitian deskriptif-kuantitatif. Sumber data diperoleh dari penyebaran kusioner dan wawancara. Sampel dalam penelitian ini berjumlah 60 Pegawai Dinas Ketahanan Provinsi Kalimantan Tengah yang dipilih dengan menggunakan Skala Likert. Metode analisis yang digunakan: Uji validitas dan uji reliabilitas. Pengujian asumsi klasik: Uji multikolinearitas, uji hesteroskedastisitas, uji normalitas, uji autokorelasi. Uji analisis regresi berganda. Dan uji hipotesis. Variabel dan indikator yang digunakan dalam penelitian ini dapat dilihat dalam tabel berikut ini:

Tabel 2. Identifikasi Variabel

\begin{tabular}{|c|c|c|c|}
\hline Variabel & Definisi Variabel & Indikator & Item \\
\hline \multirow{6}{*}{$\begin{array}{l}\text { Pengembangan } \\
\text { karir(X1). }\end{array}$} & \multirow{6}{*}{$\begin{array}{l}\text { Pengembangan karir adalah } \\
\text { Peningkatan pribadi yang dapat } \\
\text { di lakukan seseorang untuk } \\
\text { mencapai suatu rencana karir } \\
\text { yang telah di } \\
\text { rencanakan.(Handoko, dalam } \\
\text { megita,2014) }\end{array}$} & 1. Penilaian. & 1 \\
\hline & & 2. Evaluasi. & 2 \\
\hline & & 3. Prestasi kerja. & 3 \\
\hline & & 4. Jenjang Pendidikan & 4 \\
\hline & & 5. Pelatihan. & 5 \\
\hline & & 6. Lama Kerja . & 6 \\
\hline \multirow[t]{8}{*}{ Motivasi (X2). } & \multirow{8}{*}{$\begin{array}{l}\text { motivasi adalah suatu } \\
\text { perangsangan keinginan (want) } \\
\text { daya pengerak kemauan bekerja } \\
\text { seseorang, setiap motif } \\
\text { mempunyai tujuan tertentu yang } \\
\text { ingin di capai.(Malayu S.P } \\
\text { Hasibuan, dalam Danang } \\
\text { Sunyoto,2012) }\end{array}$} & $\begin{array}{l}\text { 1. Kesempatan maju atau } \\
\text { promosi }\end{array}$ & 1 \\
\hline & & 2. Keamanan Bekerja & 2 \\
\hline & & 3. Tempat kerja yang nyaman. & 3 \\
\hline & & 4. Pengakuan atau prestasi & 4 \\
\hline & & 5. Kondisi kerja yang baik & 5 \\
\hline & & $\begin{array}{l}\text { 6. Pengaharapan penuh atas } \\
\text { penyelesaian pekerjaan }\end{array}$ & 6 \\
\hline & & $\begin{array}{l}\text { 7. Intrinsik berupa penyelesaian } \\
\text { dan prestasi/pencapaian }\end{array}$ & 7 \\
\hline & & $\begin{array}{l}\text { 8. Ekstrinsik berupan finansial } \\
\text { (gajih, upah dan tunjangan) } \\
\text { antara peribadi dan promosi }\end{array}$ & 8 \\
\hline \multirow[t]{7}{*}{ Kompetensi(X3) } & \multirow{7}{*}{$\begin{array}{l}\text { kompetensi adalah karakteristik } \\
\text { yang mendasari seseorang } \\
\text { berkaitan dengan efektiviats } \\
\text { kinerja individu dalam } \\
\text { pekerjaannya atau karakteristik } \\
\text { individu yang memiliki } \\
\text { hubungan kasual atau sebab- } \\
\text { akibat dengan kriteria yang }\end{array}$} & 1. Ketepatan waktu & 1 \\
\hline & & 2. Adaptasi Kerja & 2 \\
\hline & & 3. Kemampuan mengelola & 3 \\
\hline & & 4. Kemampuan merencanakan & 4 \\
\hline & & 5. Pengambilan keputusan & 5 \\
\hline & & 6. Dukungan kerja & 6 \\
\hline & & 7. Kerjasama & 7 \\
\hline
\end{tabular}




\begin{tabular}{|c|c|c|c|}
\hline & $\begin{array}{l}\text { dijadikan acuan, efektif atau } \\
\text { kinerja prima ditempat kerja } \\
\text { pada situasi tertentu.,(Spencer } \\
\text { dalam Moehariono, 2012) }\end{array}$ & 8. Bersosialiasi & 8 \\
\hline \multirow[t]{5}{*}{ Kinerja (Y). } & \multirow{5}{*}{$\begin{array}{l}\text { Kinerja merupakan hasil kerja } \\
\text { baik itu secara kualitas maupun } \\
\text { kuantitas yang telah di capai } \\
\text { pegawai, dalam menjalankan } \\
\text { tugas-tugasnya seusai tanggung } \\
\text { jawab yang di berilan organisasi } \\
\text { dan hasil kerjanya tersebut } \\
\text { disesuaikan dengan hasil kerja } \\
\text { yang di harapkan organisasi } \\
\text { melalui kriteria-kriteria atau } \\
\text { standar kinerja pegawai.(Anwar } \\
\text { Prabu Mangkunegara,(2013) }\end{array}$} & 1. Mutu Pegawai & 1 \\
\hline & & 2. Kehadiran & 2 \\
\hline & & 3. Kerjasama & 3 \\
\hline & & 4. Tanggung Jawab & 4 \\
\hline & & 5. Pemanfaatan Waktu kerja & 5 \\
\hline
\end{tabular}

Sumber: Data sekunder dikembangkan, 2019

Data dianalisis dengan menggunakan metode Statistical Product and Service Solution (SPSS). SPSS adalah sebuah program aplikasi yang memiliki kemampuan untuk analisis statistik cukup tinggi serta sistem manajemen data pada lingkungan grafis dengan menggunakan menu-menu deskriptif dan kotak-kotak dialog yang sederhana sehingga muda dipahami untuk cara pegoprasiannya.

\section{HASIL DAN PEMBAHASAN}

Setelah pengumpulan data dengan mengunakan kuesioner yang disebarkan kepada responden yakni Mahasiswa Fakultas Ekonomi dan Bisnis Universitas Palangka Raya yang berjumlah 60 orang. Sedangkan untuk rangkuman hasil uji validitas dan hasil uji reliabilitas dapat dilihat pada Tabel 3. dan Tabel 4. sebagai berikut:

Tabel 3. Hasil Uji Validitas

\begin{tabular}{|c|c|c|c|c|}
\hline \multirow{3}{*}{ Variabel } & Item & $\mathrm{r}_{\text {hitung }}$ & $\mathrm{r}_{\text {tabel }}$ & Keterangan \\
\hline \multirow{3}{*}{ Pengembangan karir } & $\mathrm{X} 1.1$ & 0,437 & 0,254 & VALID \\
\cline { 2 - 5 } & $\mathrm{X} 1.2$ & 0,754 & 0,254 & VALID \\
\cline { 2 - 5 } & $\mathrm{X} 1.3$ & 0,609 & 0,254 & VALID \\
\cline { 2 - 5 } & $\mathrm{X} 1.4$ & 0,562 & 0,254 & VALID \\
\hline \multirow{5}{*}{ Motivasi } & $\mathrm{X} 1.5$ & 0,759 & 0,254 & VALID \\
\hline & $\mathrm{X} 1.6$ & 0,286 & 0,254 & VALID \\
\hline & $\mathrm{X} 2.1$ & 0,641 & 0,254 & VALID \\
\hline & $\mathrm{X} 2.2$ & 0,509 & 0,254 & VALID \\
\hline & $\mathrm{X} 2.3$ & 0,600 & 0,254 & VALID \\
\hline & $\mathrm{X} 2.4$ & 0,545 & 0,254 & VALID \\
\hline & $\mathrm{X} 2.5$ & 0,605 & 0,254 & VALID \\
\hline & $\mathrm{X} 2.6$ & 0,749 & 0,254 & VALID \\
\hline
\end{tabular}


Sumber: Hasil Olahan SPSS 16.0

\begin{tabular}{|c|c|c|c|c|}
\hline \multirow{5}{*}{} & $\mathrm{X} 2.7$ & 0,662 & 0,254 & VALID \\
\hline \multirow{5}{*}{ Kompetensi } & $\mathrm{X} 2.8$ & 0,639 & 0,254 & VALID \\
\hline & $\mathrm{X} 3.1$ & 0,717 & 0,254 & VALID \\
\hline \multirow{5}{*}{ Kinerja Pegawai } & $\mathrm{X} 3.2$ & 0,619 & 0,254 & VALID \\
\hline \multirow{5}{*}{} & $\mathrm{X} 3.3$ & 0,660 & 0,254 & VALID \\
\hline & $\mathrm{X} 3.4$ & 0,802 & 0,254 & VALID \\
\hline & $\mathrm{X} 3.5$ & 0,645 & 0,254 & VALID \\
\hline & $\mathrm{X} 3.6$ & 0,723 & 0,254 & VALID \\
\hline & $\mathrm{X} 3.7$ & 0,674 & 0,254 & VALID \\
\hline & $\mathrm{X} 3.8$ & 0,762 & 0,254 & VALID \\
\hline & $\mathrm{Y} 1.1$ & 0,596 & 0,254 & VALID \\
\hline & $\mathrm{Y} 1.2$ & 0,658 & 0,254 & VALID \\
\hline & $\mathrm{Y} 1.3$ & 0,672 & 0,254 & VALID \\
\hline & $\mathrm{Y} 1.4$ & 0,746 & 0,254 & VALID \\
\hline & $\mathrm{Y} 1.5$ & 0,611 & 0,254 & VALID \\
\hline
\end{tabular}

Berdasarkan Tabel 4. dimana pengujian validitas penelitian (kuesioner) dengan masing-masing pernyataan mendapatkan nilai $r_{\text {hitung }}$ lebih basar dari $r_{\text {tabel }} 0,254$. Sehingga keseluruhan kuesioner penelitian tersebut dikatakan valid.

Tabel 4. Hasil Uji Reliabilitas

\begin{tabular}{|c|c|c|c|}
\hline $\begin{array}{c}\text { Variabel } \\
\begin{array}{c}\text { Pengembangan karir } \\
\text { (X1) }\end{array}\end{array}$ & $\begin{array}{c}\text { Crombach alpha } \\
0,647\end{array}$ & Kriteria & $\begin{array}{c}\text { Keterangan } \\
\text { Reliabel }\end{array}$ \\
\hline Motivasi (X2) & 0,772 & $\begin{array}{c}\text { Crombach's } \\
\text { alpha }>0.6\end{array}$ & Reliabel \\
\cline { 1 - 1 } Kompetensi (X3) & 0,853 & & Reliabel \\
\hline Kinerja Pegawai (Y) & 0,671 & Reliabel \\
\hline
\end{tabular}

Berdasarkan Tabel 4 dimana hasil uji realibilitas tersebut menunjukan bahwa semua variabel mempunyai koefisien alpha yang cukup besar di atas 0,6 sehingga dapat dikatakan semua konsep pengukur masing - masing variabel dari kuesioner adalah reliabel yang berarti bahwa kuesioner yang digunakan dalam penelitian ini merupakan kuesioner yang reliabel atau andal.

Sedangkan untuk rangkuman tabel asumsi klasik adalah sebagai berikut:

Tabel 5 uji normalitas secara Kolmogorov-Smirnov

\begin{tabular}{|l|l|r|}
\hline \multicolumn{2}{|c|}{ One-Sample Kolmogorov-Smirnov Test } \\
\hline \multicolumn{1}{|c|}{} & \multicolumn{1}{|c|}{$\begin{array}{c}\text { Unstandardized } \\
\text { Residual }\end{array}$} \\
\hline $\mathrm{N}$ & Mean & 60 \\
\hline Normal Parameters & \\
\cline { 2 - 3 } & Std. Deviation & .0000000 \\
\hline Most Extreme & Absolute & .64175261 \\
\hline
\end{tabular}




\begin{tabular}{|l|r|r|}
\hline Differences & Positive & .096 \\
\cline { 2 - 3 } & Negative & -.139 \\
\hline Kolmogorov-Smirnov Z & 1.079 \\
\hline Asymp. Sig. (2-tailed) & .195 \\
\hline a. Test distribution is Normal.
\end{tabular}

Sumber: Hasil Olahan SPSS 16.0

Berdasarkan tabel 5 uji normalitas diketahui nilai signifikan 0,195 $>0,05$ maka dapat di simpulkan nilai residual berdistribusi Normal.

Tabel 6 Uji Multikolinearitas

\begin{tabular}{|c|c|c|c|c|c|c|c|c|}
\hline \multicolumn{9}{|c|}{ Coefficients $^{a}$} \\
\hline \multirow{2}{*}{\multicolumn{2}{|c|}{ Model }} & \multicolumn{2}{|c|}{$\begin{array}{l}\text { Unstandardized } \\
\text { Coefficients }\end{array}$} & \multirow{2}{*}{$\begin{array}{c}\text { Standardized } \\
\text { Coefficients } \\
\text { Beta }\end{array}$} & \multirow[t]{2}{*}{$\mathrm{t}$} & \multirow[t]{2}{*}{ Sig. } & \multicolumn{2}{|c|}{$\begin{array}{l}\text { Collinearity } \\
\text { Statistics }\end{array}$} \\
\hline & & B & $\begin{array}{l}\text { Std. } \\
\text { Error }\end{array}$ & & & & Tolerance & VIF \\
\hline \multirow[t]{4}{*}{1} & (Constant) & -.425 & 2.569 & & -.166 & .869 & & \\
\hline & TOTAL_X1 & .283 & .101 & 261 & 2.805 & .007 & .785 & 1.274 \\
\hline & TOTAL_X2 & .203 & .071 & .346 & 2.872 & .006 & .469 & 2.134 \\
\hline & TOTAL_X3 & .209 & .071 & .340 & 2.927 & .005 & .505 & 1.980 \\
\hline \multicolumn{4}{|c|}{ a. Dependent Variable: TOTAL_Y } & & & & & \\
\hline
\end{tabular}

Sumber: Hasil Olahan SPSS 16.0

Berdasarkan Tabel 6 dari hasil pengujian multikolinearitas, perhitungan nilai tolerance terlihat bahwa tidak ada variabel yang memiliki nilai tolerance $<0,10$, maka berarti dalam penelitian ini tidak terdapat masalah dalam uji multikolinearitas. Demikin juga hasil perhitungan VIF, dari Ketiga variabel bebas yang di uji tidak ada nilai VIF $<10,00$, maka dapat disimpulkan bahwa tidak terjadi multikolinearsitas antara variabel independen dalam model regresi.

Tabel 7 Uji Hesteroskedastisitas secara uji Glejser

\begin{tabular}{|c|c|c|c|c|c|c|}
\hline \multicolumn{7}{|c|}{ Coefficients $^{a}$} \\
\hline \multirow{2}{*}{\multicolumn{2}{|c|}{ Model }} & \multicolumn{2}{|c|}{ Unstandardized Coefficients } & \multirow{2}{*}{$\begin{array}{c}\text { Standardized } \\
\text { Coefficients } \\
\text { Beta }\end{array}$} & \multirow[t]{2}{*}{$\mathrm{t}$} & \multirow[t]{2}{*}{ Sig. } \\
\hline & & B & Std. Error & & & \\
\hline \multirow[t]{4}{*}{1} & (Constant) & -.501 & 1.875 & & -.267 & .790 \\
\hline & TOTAL_X1 & .082 & .074 & .165 & 1.116 & .269 \\
\hline & TOTAL_X2 & .026 & .052 & .097 & .507 & .614 \\
\hline & TOTAL_X3 & -.041 & .052 & -.147 & -.794 & .431 \\
\hline \multicolumn{3}{|c|}{ a. Dependent Variable: RES2 } & & & & \\
\hline
\end{tabular}

Sumber: Hasil Olahan SPSS 16.0

Berdasarkan Tabel 7 bahwa uji glejser dengan signifikansi X1(0,269), X2(0,614) dan X3 $(0,431)$ lebih dari 0,05. Maka dinyatakan bahwa tidak terjadi heteroskedastisitas. 
Tabel 8 Uji Autokorelasi Secara uji Runs Test Runs Test

\begin{tabular}{|c|c|}
\hline \multicolumn{2}{|c|}{ Runs Test } \\
\hline & Unstandardized Residual \\
\hline Test Value ${ }^{a}$ & .14813 \\
\hline Cases $<$ Test Value & 30 \\
\hline Cases $>=$ Test Value & 30 \\
\hline Total Cases & 60 \\
\hline Number of Runs & 34 \\
\hline Z & .781 \\
\hline Asymp. Sig. (2-tailed) & .435 \\
\hline a. Median & \\
\hline
\end{tabular}

Sumber: Hasil Olahan SPSS 16.0

Berdarkan tabel 8 diketahui nilai Asymp.sig (2-tailed) sebesar 0,435 >0,05, maka dapat di simpukan bahwa tidak terdapat gejala autokorelasi, sehingga analisis linear dapat dilakukan.

Tabel 9 Analisis Regresi Linear Berganda

\begin{tabular}{|c|c|c|c|c|c|c|}
\hline \multicolumn{7}{|c|}{ Coefficients $^{a}$} \\
\hline \multicolumn{2}{|c|}{ Model } & \multicolumn{2}{|c|}{ Unstandardized Coefficients } & \multirow{2}{*}{$\begin{array}{c}\text { Standardized } \\
\text { Coefficients } \\
\text { Beta }\end{array}$} & \multirow[t]{2}{*}{$\mathrm{t}$} & \multirow[t]{2}{*}{ Sig. } \\
\hline & & B & Std. Error & & & \\
\hline \multirow[t]{4}{*}{1} & (Constant) & -.425 & 2.569 & & -.166 & .869 \\
\hline & TOTAL_X1 & .283 & 101 & 261 & 2.805 & .007 \\
\hline & TOTAL_X2 & .203 & .071 & .346 & 2.872 & .006 \\
\hline & TOTAL_X3 & .209 & .071 & .340 & 2.927 & .005 \\
\hline \multicolumn{4}{|c|}{ a. Dependent Variable: TOTAL_Y } & & & \\
\hline
\end{tabular}

Sumber: Hasil Olahan SPSS 16.0

Berdasarkan Hasil tabel 9 dimana hasil analisis regresi diperoleh persamaan regresi sebagai berikut:

$$
Y=-0,425+0,283 X_{1}+0,203 X_{2}+0,209 X_{3}
$$

Tabel 10 Uji t

Coefficients $^{\mathrm{a}}$

\begin{tabular}{|c|c|c|c|c|c|c|}
\hline \multicolumn{7}{|c|}{ Coefficients $^{a}$} \\
\hline \multicolumn{2}{|c|}{ Model } & \multicolumn{2}{|c|}{ Unstandardized Coefficients } & \multirow{2}{*}{$\begin{array}{c}\text { Standardized } \\
\text { Coefficients } \\
\text { Beta }\end{array}$} & \multirow[t]{2}{*}{$\mathrm{t}$} & \multirow[t]{2}{*}{ Sig. } \\
\hline & & B & Std. Error & & & \\
\hline \multirow[t]{4}{*}{1} & (Constant) & -.425 & 2.569 & & -.166 & .869 \\
\hline & TOTAL_X1 & .283 & .101 & .261 & 2.805 & .007 \\
\hline & TOTAL_X2 & 203 & .071 & .346 & 2.872 & .006 \\
\hline & TOTAL_X3 & .209 & .071 & .340 & 2.927 & .005 \\
\hline \multicolumn{4}{|c|}{ a. Dependent Variable: TOTAL_Y } & & & \\
\hline
\end{tabular}

Sumber: Hasil Olahan SPSS 16.0 
Berdasarkan Tabel 10 hasil koefisien melalui pengujian hipotesis dan kemudian membandingkannya dengan $\mathrm{t}_{\text {tabel }}$ yaitu $\mathrm{n}=$ jumlah sampel 60 dengan $\alpha=0,05$, dan $\mathrm{K}=$ jumlah varibel bebas dan terikat Dengan rumus $d f=(\alpha / 2 ; n-k)$. maka $t_{\text {tabel }}$ sebesar 2,003 . Jadi dari hasil tiap-tiap variabel dapat diketahui variabel manakah yang berpengaruh terhadap kinerja pegawai

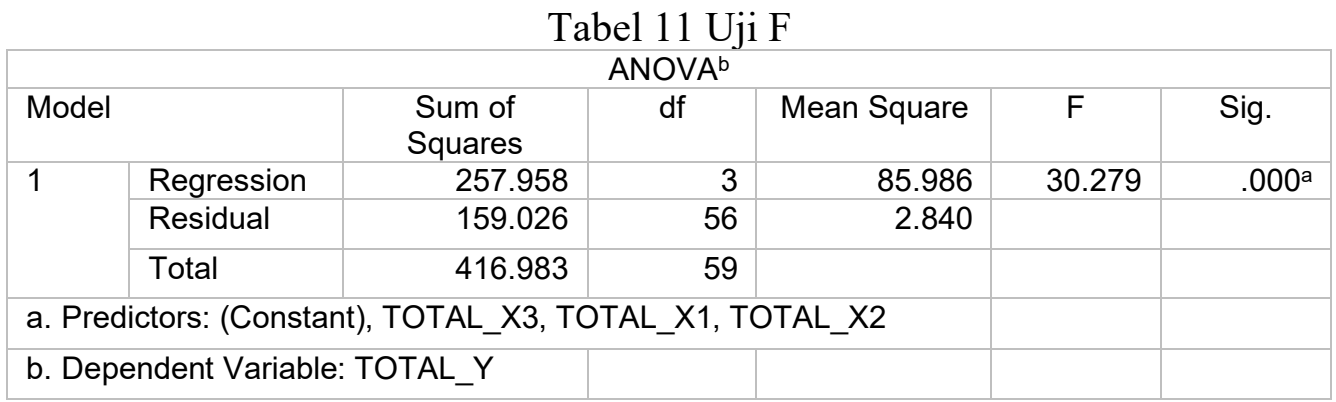

Sumber: Hasil Olahan SPSS 16.0

Berdasarkan tabel 11 hasil koefisien melalui pengujian hipotesis dan kemudaian membandingkannya dengan $F_{\text {tabel }}$ yaitu $n=$ jumlah sampel 60 dengan $K=$ jumlah varibel bebas dan terikat. Dengan rumus $\mathrm{df}=(\mathrm{k} ; \mathrm{n}-\mathrm{k})$, maka $\mathrm{F}_{\text {tabel }}$ sebesar 2,54. Berdarkan output di atas tabel 4.12 diketehui nilai signifikan untuk pengaruh $\mathrm{X} 1, \mathrm{X} 2$ dan $\mathrm{X} 3$ secara simultan Tehadap $\mathrm{Y}$ adalah sebesar $0,00<0,05$ dan nilai $\mathrm{F}_{\text {hitung }} 30,279>\mathrm{F}_{\text {tabel }} 2,54$, sehingga dapat disimpulkan bahwa $\mathrm{H} 4$ diterima yang berarti terdapat pengaruh $\mathrm{X} 1, \mathrm{X} 2$, dan $\mathrm{X} 3$ secara simultan terhadap Y.

Tabel 12 Analisis Koefisien Determinasi $\left(\mathrm{R}^{2}\right)$

Model Summaryb

\begin{tabular}{|l|r|r|r|c|}
\hline Model & $\mathrm{R}$ & $\mathrm{R}$ Square & $\begin{array}{c}\text { Adjusted R } \\
\text { Square }\end{array}$ & $\begin{array}{c}\text { Std. Error of the } \\
\text { Estimate }\end{array}$ \\
\hline 1 & $.787^{\mathrm{a}}$ & .619 & .598 & 1.68515 \\
\hline
\end{tabular}

a. Predictors: (Constant), TOTAL_X3, TOTAL_X1, TOTAL_X2

b. Dependent Variable: TOTAL_Y

Sumber: Hasil Olahan SPSS 16.0

Berdasarkan table 12 koefisien determinasi $\left(\mathrm{R}^{2}\right)$ menujukan angka $R$ Square 0,619 atau $61,9 \%$ hal ini mengadung arti bahwa pengaruh X1,X2 dan X3 secara simultan Terhadap Y adalah sebesar $61,9 \%$.

\section{SIMPULAN}

Penelitian ini bertujuan untuk menguji pengaruh pengembangan karir, motivasi dan kompetensi terhadap kinerja pegawai Dinas ketahanan Pangan Provinsi Kalimantan Tengah. Hasil penelitian menunjukkan bahwa: Pengembangan karir bepengaruh positif dan signifikan terhadap kinerja pegawai Dinas Ketahanan Pangan Provinsi Kalimantan Tengah. Motivasi berpengaruh positif dan signifikan terhdapa kinerja pegawai Dinas Ketahanan Pangan Provinsi Kalimantan Tengah. Kompetensi berpengaruh positif dan signifikan terhadap kinerja pegawai Dinas Ketahanan Pangan Provinsi Kalimantan Tengah. Pengembangan karir,motivasi dan kompetensi berpengaruh positif dan signifikan terhadap kinerja pegawai 
Dinas Ketahana Pangan Provinsi Kalimantan Tengah.

Saran yang dapat diberikan berdasarkan hasil penelitian adalah: Penelitian selanjutnya diharapkan agar mendapatkan suatu model penelitian yang baik dengan didukung oleh teori yang kuat dan disarankan untuk lebih memperbanyak referensi penelitian yang mampu mendukung topik yang diteliti.. Dinas Ketahanan Pangan Provinsi Kalimantan Tengah harus memperhatikan pengembangan karir yang ada karena variabel tersebut bepengaruh positif dan signifikan terhdap kinerja pegawai. Pelatihan yang dilakukan Dinas Ketahan Pangan Provinsi Kalimantan Tengah. sudah sangat baik akan tetapi ada baiknya apabila Dinas Ketahana Pangan Provinsi Kalimantan Tengah dapat mempertahankan program-program pelatihan saat ini. Tentunya kinerja pegawai akan lebih baik apabila dapat meningkatkan atau memperbanyak pelatihan yang sesuai dengan job specificationagar kualitas pengetahuan dan keterampilan yang dimiliki pegawai dapat bertambah dari waktu ke waktu.

\section{REFERENSI}

Afriska Tri. 2017. Pengaruh Pengembangan Karir, Motivasi Kerja dan Kompetensi terhadap Kinerja Pegawai Pada Kantor Kecamatan Belinyu Kabupaten Bangka.

Barrett, V. B. (2017). At what level is absenteeism \& turnover too high. Retrieved fromhttp://smallbusiness.chron.com/level-absenteeismturnover-high-62711.html.

Dubrin Andrew J. (2005). Leadership (Terjemahan), Edisi Kedua, Prenada Media, Jakarta.

Edwin B. Flippo. (2005). Manajemen Personalia. Jilid 2. Edisi ke-6. Terjemahan.Erlangga. Jakarta.

Ghozali, Imam. (2016). Aplikasi analisis Multivariate dengan Program IBM SPSS21 (edisi ketujuh). Semarang: Badan Penerbit Universitas Diponogoro.

Handoko.(2014). Manajemen Personalia dan Sumber Daya Manusia. Edisi kedua.UGM Yogyakarta.

Harlie. M. Pengaruh Disiplin Kerja, Motivasi dan Pengembangan Karir terhadap Kinerja Pegawai. Vol.11, No.2, Oktober 2010 (http://journal.stieikayutangi-bjm.ac.id, diakses 25 Oktober 2016)

Hasibuan, Malayu. (2011). Manajemen Sumber Daya Manusia, Edisi Revisi, Jakarta: PT Bumi Aksara.

Hendriani, Susi. Pengaruh Kompetensi, Komitmen,dan Pengembangan Karir terhadap Kinerja Pegawai. Jurnal Tepak Manajemen Bisnis. Vol.7, No.1, Januari 2015 (http://ejournal.urni.ac.id, diakses 25 Oktober 2016).

Manalu, Elpis Anto, (2012) Pengaruh Motivasi, Kepemimpinan, Dan Disiplin Terhadap Produktivitas Kerja Pegawai.Tapanuli Tengah.

Moehariono.(2012).Pengaruh Kinerja Berbasisi Komputer. Jakarta : PT Raja Grafindo Persada.

Negara, Ni Made Candra Megita Atma. Pengaruh Pengembangan Karir terhadap Kinerja Pegawai.Vol.4,No.1, 2014 (http://ejournal.undiksa.ac.id, diaskses 25 Oktober 2016).

Noe, Raymond A.(2010) Manajemen Sumber Daya Manusia. Edisi kesepuluh. Jakarta.: Indeks.

Priyatno, Duwi. (2010). Paham Analisa Statistik Data Dengan SPSS. Yogyakarta : penerbit Mediakom.

Rivai, Veitzhal \& sagala, Ella Jauvani. (2009).Mnajemen Sumber daya manusia unuk perusahaan : dari teori ke praktek jakarta : PT Rajagrafindo Perseda. 
Sugiyono. (2014). Metode Penelitian Kuantitatif dan Kualitatif. Bandung: Penerbit Alfabeta. Sunyoto, Danang. (2012). Manajemen Sumber Daya Manusia. Yogyakarta : Penerbit Nuba Medika.

Sutanto, Eddy Madiono. (2013) Pengaruh Pelatihan dan Motivasi Kerja terhadap kinerja karyawan. Surabaya.

Torang,Syamir. (2013). Organisasi \& Manajemen. Bandung : Penerbit Alfabeta.

Wibowo. (2010). Manajemen Kinerja. Jakarta : Rajawali Pers 